\title{
A Comparison of Symptoms and Signs in Patients with Inflammatory Dry Eye Disease using two Commercially Available Treatment Formulations of Cyclosporine A
}

Jonatan Olafsson ( $\nabla$ jonatanolaf@gmail.com )

University of Oslo

\section{Snorri Olafsson}

Innlandet Hospital Trust

Hugo Lewi Hammer

Oslo Metropolitan University

Behzod Tashbayev

The Norwegian Dry Eye Clinic

Øygunn A. Utheim

The Norwegian Dry Eye Clinic

\section{Xiangjun Chen}

University of Oslo

\section{Sten Raeder}

The Norwegian Dry Eye Clinic

\section{Neil Lagali}

Linköping University

\section{Darlene A. Dartt}

Schepens Eye Research Institute/Massachusetts Eye and Ear, Harvard Medical School

\section{Tor P. Utheim}

Oslo University Hospital

\section{Research Article}

Keywords: Cyclosporine eye drops, dry eye disease, dry eye disease treatment, ocular surface staining, tear film break-up time

Posted Date: August 20th, 2021

DOI: https://doi.org/10.21203/rs.3.rs-716429/v1 
License: (c) (i) This work is licensed under a Creative Commons Attribution 4.0 International License. Read Full License 


\section{Abstract}

Purpose: Dry eye (DED) is a multifactorial disease of the ocular surface in which ocular surface inflammation and damage play etiological roles. In the present study, we compared symptoms and signs in patients with DED treated with $0.1 \%$ Cyclosporine A (CsA) cationic emulsion (Ikervis, Santen) and $0.05 \%$ CsA anionic emulsion (Restasis, Allergan).

Methods: Single-center, retrospective, 202 consecutive DED patients were treated with $0.1 \%$ CsA cationic emulsion (Ikervis, $n=101$ ) or $0.05 \%$ CsA anionic emulsion (Restasis, $n=101$ ) over six months. Ophthalmological work-up included Ocular Surface Disease Index (OSDI) questionnaire, fluorescein break-up time (FBUT), fluorescein ocular surface staining (OSS), Schirmer's test, meibum expressibility (ME), and meibum quality (MQ).

Results: In both treatment groups, subgroup analysis revealed a significant improvement of OSDI only in patients with severe symptoms at baseline (OSDI 33-100). Ikervis-treated patients with OSDI <23 at baseline had a significant increase in symptoms. OSS and FBUT improved significantly in most subgroups irrespective of Ikervis or Restasis being used. Regression analysis revealed a significant superiority to Restasis with regard to FBUT improvement and superiority to lkervis in regards ME improvement.

Conclusions: We conclude that there is seemingly no substantial difference in efficacy between the two drugs. The strength of Restasis is increased efficacy at improving FBUT and of Ikervis improving ME.

\section{Introduction}

Dry eye disease (DED) is a common ophthalmic condition with prevalence ranging from $5 \%$ to $50 \%$ in the general population ${ }^{1,2}$. DED can be caused by reduced tear production, increased tear film evaporation, or a combination thereof ${ }^{3}$, resulting in symptoms such as itching, foreign body sensation, redness, soreness, burning, and ocular discomfort. The Tear Film \& Ocular Society Dry Eye Workshop II (TFOS DEWS II) definition of DED highlights "tear film instability and hyperosmolarity, ocular surface inflammation and damage, and neurosensory abnormalities" as key etiological components ${ }^{3}$. The impact of severe DED on quality of life is comparable to that of moderate angina pectoris 4,5 ; yet, with a few exceptions, such as Cyclosporine $A(C s A)$ and more recently lifitegrast, most available treatments are palliative.

It is well established that inflammation triggered by both innate and adaptive immune responses is critical to the pathogenesis and chronicity of DED ${ }^{6}$. In DED, reduced tear production or increased tear evaporation can lead to the tear film becoming hyperosmolar, with increased matrix metalloprotease concentrations and cytokine imbalance ${ }^{7}$. Tear hyperosmolarity is central to the vicious cycle in DED pathophysiology, as it induces corneal and conjunctival cell apoptosis by triggering an inflammatory 
cascade reaction. Driven by a T-cell-mediated response, the inflammatory cascade further causes apoptosis and loss of mucin-producing goblet cells ${ }^{8-11}$.

There is a wide range of pharmacologic and non-pharmacologic treatment strategies for DED including artificial tears, antibiotics, topical steroids, topical CsA, and warm compresses ${ }^{12}$. First-line therapies usually include artificial tears; however, in many patients this is not sufficient to resolve the underlying inflammation. A metabolite derived from the fungi Tolypocladium inflatum and Beauveria nevus ${ }^{13}, \mathrm{CsA}$ is an immune modulator that functions by inhibiting T-cell activity by downregulating interleukin (IL)-2 protein expression and gene transcription ${ }^{14,15}$. Consequently, the vicious cycle of DED could be interrupted by CsA.

Until the recent (2018) approval by the U.S. Food and Drug Administration (FDA) of Cequa (Sun Pharma, Mumbai, India), there have been two commercially available topical CsA formulations ${ }^{13}$ on the market: CsA cationic emulsion (Ikervis, Santen, Solna, Sweden) and 0.05\% CsA emulsion of castor oil-in-water (Restasis, Allergan, Dublin, Ireland). The FDA approved Restasis in 2002, whereas Ikervis was approved by the European Medicines Agency in 2015.

Despite the widespread use of these two medications, there is no published study comparing their effects in humans. A recent study by Daull et al. demonstrated that both Ikervis and Restasis are able to reduce corneal epithelial lesions by modulating inflammation-related genes in a mouse model of DED ${ }^{16}$. Although the genes were modulated in different manners between the CsA formulations, no conclusion on superiority was made ${ }^{16}$. In an in-vitro study on human corneal epithelial cells, Hwang et al. showed that Ikervis had more potent anti-inflammatory and antiapoptotic effects than Restasis, though the clinical significance of this has not been studied ${ }^{17}$.

In the present study, we aimed to compared the efficacy of Ikervis and Restasis for treating DED.

\section{Methods}

\section{Ethics}

The study was conducted in accordance with the Declaration of Helsinki. The Regional Committee for Medical \& Health Research Ethics (REC), Section C, South East Norway, reviewed the use of the data from the Norwegian Dry Eye Clinic for the study (reference: 2013/812). The REC found the research project's "Evaluation of data from the Norwegian Dry Eye Clinic" to be outside the remit of the Act on Medical and Health Research (2008) and therefore its implementation did not require REC approval. A REC letter of exemption has been provided. Written informed consent was obtained from all participants' prior data collection.

\section{Patients}


At their initial visit to the Norwegian Dry Eye Clinic, a total of 1816 patients with DED consented to their data being collected and used for research purposes. Patients treated between 2012 to 2017 were consecutively reviewed. To be included in the study, the patients had to have received either Ikervis or Restasis and attended both first-time consultation (baseline) and a 6-month follow-up. Patients who had received both drugs were excluded. In addition to CsA, all patients received preservative-free tear substitutes. A warming device and eyelid hygiene were recommended to patients with meibomian gland dysfunction (MGD). Informed consent for the use of anonymized data for research and publication was obtained from all patients.

\section{Ophthalmological work-up}

The patients completed a self-report questionnaire on symptoms of ocular dryness (Ocular Surface Disease Index [OSDI] ${ }^{18}$, followed by a comprehensive ophthalmological work-up that included 1) assessment of ocular surface staining (OSS) after administration of $5 \mu 120 \mathrm{mg} / \mathrm{ml}$ sodium fluorescein scored with the Oxford grading scheme ${ }^{19}$, 2) fluorescein break-up time (FBUT) measured in seconds from a blink until the first appearance of a dry spot on the tear film ${ }^{20,21}, 3$ ) Schirmer's test without anesthesia (measured in mm) ${ }^{20}$, and 4) meibum expressibility (ME) ${ }^{22}$, and meibomian quality (MQ) ${ }^{22}$. Only data collected from the right eye were analyzed. All examinations were performed at the same clinic.

\section{Statistical analysis}

Data are reported as the mean and standard deviation. A significance level of $p<0.05$ was used throughout the study (SPSS ver. 24.0). Linear regression models were fitted to test if there are any significant differences in reduction of symptoms between the two treatments (Restasis or Ikervis). The models were fitted with changes in the different ophthalmological scores over the treatment period as the dependent variables. The treatment type was included as an independent variable. The change in ophthalmological scores over the treatment period may depend on the scores before treatment and is included as an independent variable. Further, patient age and sex are included as independent variables.

We evaluated the changes in OSS, FBUT, ME, and MQ values with Wilcoxon's signed rank test (non-normal distribution) and OSDI scores with a paired sample $t$-test. Intergroup differences in age and OSDI were analyzed with an independent sample $t$-test (normal distribution), differences in sex with a chi-square test, and OSS, FBUT, ME, and MQ values were analyzed with the Mann-Whitney U test.

Patients were further divided into six subgroups based on baseline OSS values (Oxford grading scheme values of $0,1,2,3,4,5+)$, five subgroups based on baseline FBUT $(1,2,3,4,>5$ seconds), and four subgroups based on baseline OSDI score (normal [0-12], mild [13-22], moderate [23-32], severe [33$100]$ ). In the subgroup analyses of pre/post-treatment OSS, FBUT, and OSDI, values were evaluated with Wilcoxon's signed rank test due to the small sample size. 


\section{Results}

\section{Patient demographics}

A total of 202 patients were included in the analysis. We included all patients who matched the inclusion criteria. By chance the groups ended up being equal in size (Fig. 1). The mean age of the lkervis and Restasis group was $52 \pm 16$ years and $54 \pm 16$ years, respectively $(p=0.28)$. Table 1 shows the age distribution between the groups. The majority of the patients were women, as is previously reported in patients with DED ${ }^{23}$. Sex distribution was equal: women constituted $72 \%$ and $81 \%$ of the lkervis and Restasis group, respectively $(p=0.13)$, thus the two groups were the same with respect to age and sex.

Table 1

Patient demographics

\begin{tabular}{|llll|}
\hline & Ikervis & Restasis & P-value \\
\hline Mean age & $52 \pm 16$ & $54 \pm 16$ & 0.28 \\
\hline $0-20$ & 1 & 0 & \\
\hline $21-30$ & 9 & 10 & \\
\hline $31-40$ & 18 & 15 & \\
\hline $41-50$ & 22 & 19 & \\
\hline $51-60$ & 21 & 15 & \\
\hline $61-70$ & 18 & 26 & \\
\hline $71-80$ & 4 & 12 & \\
\hline $81+$ & 7 & 3 & \\
\hline Sex (female) & $72 \%$ & $81 \%$ & 0.13 \\
\hline
\end{tabular}

\section{Dry eye parameters before treatment}

At baseline, the Ikervis group had higher OSS, shorter FBUT, lower OSDI score, higher ME, and higher MQ, whereas the Schirmer's test score was not significantly different between the two groups $(p=0.41)$ (Fig. 2).

\section{Changes in clinical signs and subjective symptoms after six months of treatment}

The results of the regression analysis are shown in Table 2. The first row shows the change in the ophthalmological scores using Ikervis for a typical patient, i.e. female of 52 years with an average value of each parameter at baseline. A significant improvement in OSS, FBUT and ME was observed for such a 
patient, indicating both treatments' effectiveness at treating DED. The second row shows how the change in the ophthalmological scores depend on the baseline data. These results indicate, for all parameters, that the treatment effect is greater for higher baseline values. These results are explored further below in the subgroup analysis.

Table 2

Results of the regression analysis

\begin{tabular}{|c|c|c|c|c|c|c|}
\hline & $\begin{array}{l}\text { Change in } \\
\text { OSS } \\
(95 \% \mathrm{Cl})\end{array}$ & $\begin{array}{l}\text { Change in } \\
\text { FBUT } \\
(95 \% \mathrm{Cl})\end{array}$ & $\begin{array}{l}\text { Change in } \\
\text { OSDI } \\
(95 \% \mathrm{Cl})\end{array}$ & $\begin{array}{l}\text { Change in } \\
\text { Schirmer } \\
(95 \% \mathrm{Cl})\end{array}$ & $\begin{array}{l}\text { Change in } \\
\text { ME } \\
(95 \% \mathrm{Cl})\end{array}$ & $\begin{array}{l}\text { Change } \\
\text { in MQ } \\
(95 \% \\
\text { Cl) }\end{array}$ \\
\hline \multirow{2}{*}{$\begin{array}{l}\text { For the "typical" } \\
\text { patient }^{\text {a }}\end{array}$} & $-1.58 * \star \star$ & $2.44^{\star \star \star}$ & -2.36 & 2.12 & $0.45^{\star \star \star}$ & -0.75 \\
\hline & $\begin{array}{l}(-1.82, \\
-1.34)\end{array}$ & $\begin{array}{l}(1.51, \\
3.37)^{\prime}\end{array}$ & $\begin{array}{l}(-7.02, \\
2.31)\end{array}$ & $(-0.21,4,45)$ & $(0.27,0.62)$ & $\begin{array}{l}(-1.82, \\
0.31)\end{array}$ \\
\hline \multirow{2}{*}{$\begin{array}{l}\text { Compared to } \\
\text { baseline }^{\text {b }}\end{array}$} & $-0.75^{\star \star \star}$ & $-0.45^{\star \star \star}$ & $-0.55^{\star \star \star}$ & $-0.29 * \star$ & $-0.63^{\star \star \star}$ & $-0.67 \star \star \star *$ \\
\hline & $\begin{array}{l}(-0.82 \\
-0.67)\end{array}$ & $\begin{array}{l}(-0.68 \\
-0.21)\end{array}$ & $\begin{array}{l}(-0.71 \\
-0.39)\end{array}$ & $(-0.50,-0.08)$ & $(-077,-0.49)$ & $\begin{array}{l}(-0.80 \\
0.54)\end{array}$ \\
\hline \multirow{2}{*}{$\begin{array}{l}\text { Treatment } \\
\text { comparisonc }\end{array}$} & 0.02 & $1.36^{\star}$ & -2.64 & -0.87 & $-0.89 \star \star \star$ & -0.98 \\
\hline & $\begin{array}{l}(-0.29 \\
0.33)\end{array}$ & $\begin{array}{l}(0.17 \\
2.55)\end{array}$ & $\begin{array}{l}(-10.67 \\
5.40)\end{array}$ & $(-4.19,2.46)$ & $\begin{array}{l}(-1.17 \\
-0.62)\end{array}$ & $\begin{array}{l}(-2.52 \\
0.56)\end{array}$ \\
\hline \multirow[t]{2}{*}{$\operatorname{Sex}^{d}$} & -0.29 & $1.95^{\star \star}$ & -0.22 & -1.86 & -0.021 & -0.15 \\
\hline & $\begin{array}{l}(-0.65 \\
0.07)\end{array}$ & $\begin{array}{l}(0.53 \\
3.38)\end{array}$ & $\begin{array}{l}(-8.23 \\
7.78)\end{array}$ & $(-5.64,1.93)$ & $\begin{array}{l}(-0.26 \\
0.22)\end{array}$ & $\begin{array}{l}(-1.74 \\
1.44)\end{array}$ \\
\hline \multirow[t]{2}{*}{$\mathrm{Age}^{\mathrm{e}}$} & -0.0001 & $-0.04 *$ & 0.045 & 0.05 & 0.007 & -0.039 \\
\hline & $\begin{array}{l}(-0.01 \\
0.01)\end{array}$ & $\begin{array}{l}(-0.08 \\
-0.01)\end{array}$ & $\begin{array}{l}(-0.16 \\
0.25)\end{array}$ & $(-0.06,0.15)$ & $(0.00,0.01)$ & $\begin{array}{l}(-0.08, \\
0.01)\end{array}$ \\
\hline \multicolumn{7}{|c|}{$\begin{array}{l}\text { aFrom baseline to six months for a female patient using Ikervis with an average value of the } \\
\text { parameter and average age. A significant positive value indicates an increase in the value of the } \\
\text { parameter after six months }\end{array}$} \\
\hline \multicolumn{7}{|c|}{$\begin{array}{l}{ }^{b} \text { A significant negative value indicates that the change in the parameter decreases with a higher } \\
\text { baseline value, (for example the greater the baseline value of OSS, the greater the decrease) }\end{array}$} \\
\hline \multicolumn{7}{|c|}{${ }^{\mathrm{C}} \mathrm{A}$ significant value shows a significant difference in the effect of using Restasis compared to Ikervis } \\
\hline \multicolumn{7}{|c|}{${ }^{\mathrm{d}}$ A significant value shows significant difference in effect for male and female } \\
\hline \multicolumn{7}{|c|}{${ }^{\mathrm{e} A}$ significant value shows significant change in effect with age } \\
\hline \multicolumn{7}{|c|}{$\begin{array}{l}{ }^{*} \mathrm{p}<0.05 ;{ }^{* \star} \mathrm{p}<0.01 ;{ }^{* \star *} \mathrm{p}<0.001 \text {; Cl: Confidence interval; OSS: Ocular surface staining; FBUT: } \\
\text { Fluorescein break-up time; OSDI: Ocular Surface Disease Index; ME: Meibomian expressibility; MQ: } \\
\text { Meibomian quality }\end{array}$} \\
\hline
\end{tabular}


The third row shows the difference in effect using Restasis instead of Ikervis. Restasis has $1.36 \mathrm{~s} \mathrm{higher}$ increase in FBUT than Ikervis $(p=0.026)$. Restasis also results in 0.89 less improvement in ME than Ikervis $(p<0.001)$. The fourth row shows that male patients have 1.95 higher increase in FBUT than female patients. There was no difference in the other measured parameters. The fifth row shows that the change in FBUT is reduced by $0.04 \mathrm{~s}$ per year $(p=0.027)$, indicating that the treatment effect is reduced with increasing age.

Table 3shows the means of the different parameters at baseline at six months follow-up without any statistical corrections. It shows significant improvement for OSS and FBUT for both treatments, whereas OSDI is only improved by Restasis. 
Table 3

Comparisons of Ikervis and Restasis over six months.

\begin{tabular}{|c|c|c|c|c|}
\hline & & Before & After & P-value \\
\hline \multirow[t]{4}{*}{ OSS (AU) } & Ikervis & $3.09 \pm 2.17$ & $1.04 \pm 1.26$ & $<0.001$ \\
\hline & $n=100$ & & & \\
\hline & Restasis & $2.04 \pm 2.02$ & $0.82 \pm 1.15$ & $<0.001$ \\
\hline & $\mathrm{n}=100$ & & & \\
\hline \multirow[t]{4}{*}{ FBUT (s) } & Ikervis & $3.01 \pm 2.73$ & $6.19 \pm 4.42$ & $<0.001$ \\
\hline & $n=101$ & & & \\
\hline & Restasis & $3.61 \pm 2.52$ & $7.60 \pm 4.89$ & $<0.001$ \\
\hline & $n=101$ & & & \\
\hline \multirow[t]{4}{*}{ OSDI (AU) } & Ikervis & $31.8 \pm 20.4$ & $32.8 \pm 19.3$ & 0.64 \\
\hline & $n=83$ & & & \\
\hline & Restasis & $52.5 \pm 22.3$ & $39.6 \pm 23.1$ & 0.006 \\
\hline & $n=36$ & & & \\
\hline \multirow[t]{4}{*}{ Schirmer (mm) } & Ikervis & $11.06 \pm 6.71$ & $12.83 \pm 9.80$ & 0.32 \\
\hline & $n=53$ & & & \\
\hline & Restasis & $11.16 \pm 9.61$ & $11.97 \pm 9.26$ & 0.40 \\
\hline & $n=37$ & & & \\
\hline \multirow[t]{4}{*}{ ME (AU) } & Ikervis & $2.11 \pm 0.65$ & $2.27 \pm 0.66$ & 0.054 \\
\hline & $\mathrm{n}=94$ & & & \\
\hline & Restasis & $1.69 \pm 0.54$ & $1.62 \pm 0.62$ & 0.59 \\
\hline & $\mathrm{n}=29$ & & & \\
\hline \multirow[t]{4}{*}{$M Q(A U)$} & Ikervis & $10.93 \pm 4.94$ & $9.13 \pm 4.71$ & 0.01 \\
\hline & $\mathrm{n}=82$ & & & \\
\hline & Restasis & $7.98 \pm 5.16$ & $7.13 \pm 4.39$ & 0.26 \\
\hline & $\mathrm{n}=48$ & & & \\
\hline $\begin{array}{l}\text { Means with sta } \\
\text { staining; FBUT: } \\
\text { expressibility; }\end{array}$ & $\begin{array}{l}\text { ion at ba } \\
\text { break-up } \\
\text { quality; } s\end{array}$ & $\begin{array}{l}\text { id six mont } \\
\text { DI: ocular } \\
\text { s; mm: mill }\end{array}$ & $\begin{array}{l}\text { eatment. OS } \\
\text { ease index: } \\
\text { J: arbitrary }\end{array}$ & $\begin{array}{l}\text { surface } \\
\text { um }\end{array}$ \\
\hline
\end{tabular}




\section{Subgroup analysis}

In subgroups arranged by baseline OSS, all subgroups had significantly improved OSS post-treatment except patients with baseline OSS of 0 in the Ikervis groups and patients with baseline OSS of 0 and 1 in the Restasis groups (Table 4). In subgroups categorized by baseline FBUT, all patients had significantly improved FBUT, apart from Restasis-treated patients with a baseline score of $\geq 5$ seconds (Table 5). In subgroups sorted by baseline OSDI scores, only the subgroup with severe symptoms (OSDI score $\geq 33$ ) demonstrated improvement in both treatment groups (Table 6). Those with moderate symptom (OSDI score 23-32) had no change in either group, and lkervis-treated patients with a baseline OSDI of less than 22 had an increase during the course of treatment. There were only two Restasis patients in the latter group so they could not be analyzed.

Table 4. Subgroup analysis for ocular surface staining (OSS)

\begin{tabular}{|c|c|c|c|c|c|c|c|c|c|}
\hline \multirow{2}{*}{$\begin{array}{l}\text { Ikervis } \\
\text { Staining* }\end{array}$} & & \multicolumn{8}{|c|}{ Restasis } \\
\hline & & Mean & S.D. & $\mathbf{n}$ & $\begin{array}{l}\mathrm{P}- \\
\text { value }\end{array}$ & Mean & S.D. & $\mathrm{n}$ & $\begin{array}{l}\mathrm{P}- \\
\text { value }\end{array}$ \\
\hline \multirow[t]{2}{*}{0} & Before & 0 & 0 & \multirow[t]{2}{*}{20} & \multirow[t]{2}{*}{0.024} & 0 & 0 & \multirow[t]{2}{*}{13} & \multirow[t]{2}{*}{0.066} \\
\hline & After & 0.45 & 0.83 & & & 0.54 & 0.97 & & \\
\hline \multirow[t]{2}{*}{1} & Before & 1 & 0 & \multirow[t]{2}{*}{25} & \multirow[t]{2}{*}{0.003} & 1 & 0 & \multirow[t]{2}{*}{8} & \multirow[t]{2}{*}{0.257} \\
\hline & After & 0.44 & 0.77 & & & 0.63 & 0.92 & & \\
\hline \multirow[t]{2}{*}{2} & Before & 2 & 0 & \multirow[t]{2}{*}{29} & \multirow[t]{2}{*}{$<0.001$} & 2 & 0 & \multirow[t]{2}{*}{18} & \multirow[t]{2}{*}{0.001} \\
\hline & After & 0.72 & 1.22 & & & 0.89 & 0.76 & & \\
\hline \multirow[t]{2}{*}{3} & Before & 3 & 0 & \multirow[t]{2}{*}{10} & \multirow[t]{2}{*}{0.007} & 3 & 0 & \multirow[t]{2}{*}{24} & \multirow[t]{2}{*}{$<0.001$} \\
\hline & After & 1.30 & 0.95 & & & 1.00 & 1.22 & & \\
\hline \multirow[t]{2}{*}{4} & Before & 4 & 0 & \multirow[t]{2}{*}{6} & \multirow[t]{2}{*}{0.026} & 4 & 0 & \multirow[t]{2}{*}{20} & \multirow[t]{2}{*}{$<0.001$} \\
\hline & After & 1.17 & 0.98 & & & 0.75 & 1.29 & & \\
\hline \multirow[t]{2}{*}{$5+$} & Before & 6.70 & 2.26 & \multirow[t]{2}{*}{10} & \multirow[t]{2}{*}{0.005} & 6.65 & 2.18 & \multirow[t]{2}{*}{17} & \multirow[t]{2}{*}{$<0.001$} \\
\hline & After & 2.10 & 1.60 & & & 1.87 & 1.51 & & \\
\hline
\end{tabular}


Table 5

Subgroup analysis for fluorescein break-up time (FBUT) values

\begin{tabular}{|lllllllllll|}
\hline & \multicolumn{3}{c}{ Ikervis } & \multicolumn{7}{c|}{ Restasis } \\
\hline FBUT & & Mean & S.D. & $\mathbf{n}$ & P-value & Mean & S.D. & $\mathbf{n}$ & P-value \\
$\mathbf{1}$ & Before & 1 & 0 & 13 & 0.0014 & 1 & 0 & 28 & $<0.001$ \\
& After & 5.46 & 2.99 & & & 4.21 & 2.63 & \\
\hline $\mathbf{2}$ & Before & 2 & 0 & 30 & $<0.001$ & 2 & 0 & 33 & $<0.001$ \\
& After & 8.17 & 5.68 & & & 5.18 & 3.22 & & \\
$\mathbf{3}$ & Before & 3 & 0 & 18 & $<0.001$ & 3 & 0 & 17 & $<0.001$ \\
& After & 6.33 & 2.77 & & & 5.82 & 2.81 & & \\
\hline $\mathbf{4}$ & Before & 4 & 0 & 11 & 0.031 & 4 & 0 & 8 & 0.018 \\
& After & 5.18 & 1.54 & & & 10.50 & 5.48 & & \\
\hline $\mathbf{5 +}$ & Before & 6.89 & 2.36 & 28 & 0.0095 & 8.71 & 3.20 & 14 & 0.33 \\
& After & 9.57 & 5.75 & & & 10.64 & 6.34 & & \\
\hline
\end{tabular}

Table 6

Subgroup analysis for Ocular Surface Disease Index (OSDI) scores

\begin{tabular}{|c|c|c|c|c|c|c|c|c|c|}
\hline Ikervis & & & & & Restasis & & & & \\
\hline OSDI & & Mean & S.D. & $\mathrm{n}$ & P-value & Mean & S.D. & $n$ & P-value \\
\hline \multirow[t]{2}{*}{$0-12$} & Before & 6.4 & 3.4 & \multirow[t]{2}{*}{14} & \multirow[t]{2}{*}{0.003} & 6.3 & 5.9 & \multirow[t]{2}{*}{2} & \multirow[t]{2}{*}{0.66} \\
\hline & After & 21.7 & 13.6 & & & 9.1 & 6.9 & & \\
\hline \multirow[t]{2}{*}{$13-22$} & Before & 16.9 & 3.0 & \multirow[t]{2}{*}{17} & \multirow[t]{2}{*}{0.011} & \multirow[t]{2}{*}{ - } & \multirow[t]{2}{*}{-} & \multirow[t]{2}{*}{0} & \multirow[t]{2}{*}{ - } \\
\hline & After & 29.8 & 19.0 & & & & & & \\
\hline \multirow[t]{2}{*}{$23-32$} & Before & 26.6 & 3.3 & \multirow[t]{2}{*}{18} & \multirow[t]{2}{*}{0.94} & 25.5 & 4.0 & \multirow[t]{2}{*}{4} & \multirow[t]{2}{*}{0.72} \\
\hline & After & 26.3 & 13.0 & & & 29.3 & 23.0 & & \\
\hline \multirow[t]{2}{*}{$33-100$} & Before & 52.5 & 13.4 & \multirow[t]{2}{*}{34} & \multirow[t]{2}{*}{0.003} & 59.1 & 17.4 & \multirow[t]{2}{*}{30} & \multirow[t]{2}{*}{0.004} \\
\hline & After & 42.4 & 20.4 & & & 43.0 & 22.3 & & \\
\hline
\end{tabular}




\section{Discussion}

Ikervis and Restasis treatment of DED was effective, as both improved OSS and FBUT. Fluorescein staining as measured by OSS is a well-established method for evaluating the health of the ocular surface and its barrier function; hence, improved staining values would be of particular interest as they indicate improvement in ocular surface integrity. Previous studies have shown that Restasis decreases OSS and improves OSDI, Schirmer's test, and FBUT ${ }^{24-27}$. Similar results have been shown for Ikervis, with significant improvement as early as 1 month after the initiation of treatment ${ }^{28-30}$. Our results found no major differences between the improvement in the two groups. High OSS at baseline appeared to result in a greater response to treatment.

The Schirmer's test with anesthesia is a measure of baseline tear production, whereas the test without anesthesia measures the combination of baseline and reflex tear production as the ocular surface is irritated by the paper strip. Wan et al. hypothesized that the improved OSS, a sign of decreased inflammation and improved ocular surface epithelial quality, results in decreased sensory-driven reflex tear production ${ }^{24}$. The authors supported this assertion by demonstrating a significant increase in the score for the Schirmer's test without local anesthesia along with an improvement in OSS. On the contrary, the patients in the present study had consistently undergone the Schirmer's test without anesthesia and did not show any improvement. Sall et al. have reported the same findings as the present study 25 .

The subgroup and regression analysis showed that patients with severe symptoms (OSDI score $>33$ ) at baseline were the only ones to show significant improvements in symptoms after treatment in both groups. A change in OSDI score by $\geq 10$ is considered clinically significant ${ }^{31}$. Leonardi et al. reported a significant decrease in OSDI score by 14.4 after 6-months Ikervis use ${ }^{29}$. Baudouin et al. demonstrated similar results in their Ikervis study ${ }^{28}$, and many studies have shown clinically significant improvements by Restasis ${ }^{32-34}$. The OSDI results in our study agree with those in the previous studies for patients with severe symptoms.

Interestingly, we found that Ikervis-treated patients with none or mild symptoms at baseline had a significant increase in symptoms over six months. There were not enough Restasis-treated patients in these subgroups for a similar analysis. Ikervis is known to cause pain upon instillation ${ }^{28}$ and the OSDIquestionnaire requires the patients to answer if they have had any ocular discomfort in the last week ${ }^{18}$. As the side-effects of Ikervis includes discomfort, this may have confounded the OSDI-results. Patients with few dry eye related complaints at baseline should be warned of a potential increase in symptoms during the initial six months of treatment. Further and larger long-term studies, however, are warranted to draw more certain conclusions.

The tear film is a complex fluid that protects the ocular surface. Tear film instability, a key finding in DED, causes more frequent blinking, which may lead to interference with visual tasks and to visual fatigue. The tear film is restored after a blink, when fluid secretion from the meibomian glands is released onto the ocular surface. The stability of the tear film can be quantified with FBUT, which improved significantly 
after treatment with both drugs when baseline FBUT was under five seconds. This was seen in previous studies for both drugs ${ }^{24,26,28}$. Interestingly, our findings show that Restasis patients had a larger increase in FBUT than Ikervis. The treatment was also more effective at increasing FBUT in males and in younger patients.

The anti-inflammatory effect of CsA is beneficial for treating MGD as it may improve MQ ${ }^{35-38}$. In the present study, all patients had MGD to a certain degree, with decreased FBUT and increased MQ and ME, and they were instructed to undergo warming therapy in addition to CsA treatment, although compliance is unknown. MGD is the leading cause of DED and has been associated with increased levels of inflammatory cytokines in tear fluids, such as IL-1, IL-6, IL-8, IL-12, epidermal growth factor, and tumor necrosis factor-alpha 39,40 . Of special interest is IL-6, the levels of which differ most greatly between healthy and dry eyes ${ }^{41,42}$. CsA can decrease IL-6, which may explain its usefulness for treating DED caused by MGD ${ }^{43}$. In our study, both drugs improved FBUT significantly with some superiority to Restasis, whereas Ikervis showed superiority in regards to ME improvement. Hence, both drugs seem to be effective at treating MGD.

Our study has some limitations. A retrospective study design is not ideal for comparing two drugs and therefore offers a lower level of evidence compared to a prospective randomized controlled study. The data for this study was collected over a period of many years, and during this time the operating procedure at the clinic evolved and more data was gradually collected at control visits. As a result, the number of parameters included at six months follow-up is not the same for all the patients, offering less evidence for our results on ME, MQ, and OSDI. The major strength of this study beside sample size is that there is no other comparisons of these two drugs in the scientific literature. Thus, our results offer a unique insight into their efficacies.

In conclusion, our study does not indicate a substantial difference in efficacy between the two drugs as both Restasis and Ikervis caused objective and subjective improvement in DED patients. The severity of DED appears to be a good indicator for therapy response in both groups, with Restasis being more effective at improving FBUT and lkervis more effective at improving ME.

\section{Declarations}

\section{Acknowledgements/Disclosures}

a. Financial support for this study was provided by the Faculty of Medicine, University of Oslo.

b. Snorri Olafsson is on the speaker bureau for Takeda Pharmaceuticals.

Tor Paaske Utheim is co-founder and co-owner of The Norwegian dry eye clinic, which delivers talks for and/or receives financial support from the following: ABIGO, Alcon, Allergan, AMWO, Bausch\&Lomb, European school for advanced studies in ophthalmology, InnZ Medical, Medilens Nordic, Medistim, 
Novartis, Santen, Specsavers, Shire and Thea Laboratoires. He has served on the global scientific advisory board for Novartis and Alcon as well as the European advisory board for Shire. Utheim is the Norwegian Global Ambassador for Tear Film and Ocular Surface Society (TFOS) and a board member of the International Ocular Surface Society.

Sten Raeder has financial disclosers for Abigo, Alcon, AMWO, Bausch \& Lomb, Medilens, Medistim, Novartis, Santen, Théa. In addition, he has co-founded the Norwegian Dry Eye Clinic. Darlene Dartt is a consultant for Coopervision.

c. The authors wish to thank the Department of Biostatistics, Faculty of Medicine, University of Oslo, for help with the statistical analysis.

\section{Author contribution statements}

$\mathrm{JO}$ and $\mathrm{SO}$ wrote the manuscript. $\mathrm{JO}$ and $\mathrm{HLH}$ performed the statistical analysis and made the tables and graphs. BT, OAU, XC, and SR collected the data. DAD and TPU planned the study. All authors reviewed the manuscript.

\section{References}

1. The epidemiology of dry eye disease: report of the Epidemiology Subcommittee of the International Dry Eye WorkShop (2007). The ocular surface 5, 93-107 (2007).

2. Stapleton, F. et al. The ocular surface, 15, 334-365 https://doi.org/10.1016/j.jtos.2017.05.003 (2017).

3. Craig, J. P. et al. TFOS DEWS II Definition and Classification Report. The ocular surface, 15, 276-283 https://doi.org/10.1016/j.jtos.2017.05.008 (2017).

4. Buchholz, P. et al. Utility assessment to measure the impact of dry eye disease. The ocular surface, 4, 155-161 (2006).

5. Schiffman, R. M. et al. Utility assessment among patients with dry eye disease., 110, 1412-1419 https://doi.org/10.1016/s0161-6420(03)00462-7 (2003).

6. Bron, A. J. et al. TFOS DEWS II pathophysiology report. The ocular surface, 15, 438-510 https://doi.org/10.1016/j.jtos.2017.05.011 (2017).

7. The definition and classification of dry eye disease: report of the Definition and Classification Subcommittee of the International Dry Eye WorkShop (2007). The ocular surface 5, 75-92 (2007).

8. Stevenson, W., Chauhan, S. K. \& Dana, R. Dry eye disease: an immune-mediated ocular surface disorder. Arch. Ophthalmol, 130, 90-100 https://doi.org/10.1001/archophthalmol.2011.364 (2012).

9. Luo, L., Li, D. Q., Corrales, R. M. \& Pflugfelder, S. C. Hyperosmolar saline is a proinflammatory stress on the mouse ocular surface. Eye \& contact lens, 31, 186-193 (2005). 
10. Luo, L. et al. Experimental dry eye stimulates production of inflammatory cytokines and MMP-9 and activates MAPK signaling pathways on the ocular surface. Invest. Ophthalmol. Vis. Sci, 45, 42934301 https://doi.org/10.1167/iovs.03-1145 (2004).

11. Baudouin, C. et al. Role of hyperosmolarity in the pathogenesis and management of dry eye disease: proceedings of the OCEAN group meeting. The ocular surface 11, 246-258, doi:10.1016/j.jtos.2013.07.003 (2013).

12. Management therapy of dry eye disease: report of the Management and Therapy Subcommittee of the International Dry Eye WorkShop(2007). The ocular surface 5, 163-178 (2007).

13. Agarwal, P. \& Rupenthal, I. D. Modern approaches to the ocular delivery of cyclosporine A. Drug discovery today, 21, 977-988 https://doi.org/10.1016/j.drudis.2016.04.002 (2016).

14. Nussenblatt, R. B. \& Palestine, A. G. Cyclosporine: immunology, pharmacology and therapeutic uses. Surv. Ophthalmol, 31, 159-169 (1986).

15. Donnenfeld, E. \& Pflugfelder, S. C. Topical ophthalmic cyclosporine: pharmacology and clinical uses. Surv. Ophthalmol, 54, 321-338 https://doi.org/10.1016/j.survophthal.2009.02.002 (2009).

16. Daull, P. et al. Modulation of Inflammation-Related Genes in the Cornea of a Mouse Model of Dry Eye upon Treatment with Cyclosporine Eye Drops. Curr. Eye Res, 44, 476-485 https://doi.org/10.1080/02713683.2018.1563197 (2019).

17. Hwang, S. B. et al. Protective Effects of Cyclosporine A Emulsion Versus Cyclosporine A Cationic Emulsion Against Desiccation Stress in Human Corneal Epithelial Cells., 39, 508-513 https://doi.org/10.1097/ico.0000000000002244 (2020).

18. Schiffman, R. M., Christianson, M. D., Jacobsen, G., Hirsch, J. D. \& Reis, B. L. Reliability and validity of the Ocular Surface Disease Index. Arch. Ophthalmol, 118, 615-621 (2000).

19. Bron, A. J., Evans, V. E. \& Smith, J. A. Grading of corneal and conjunctival staining in the context of other dry eye tests., 22, 640-650 (2003).

20. Bron, A. J. Diagnosis of dry eye. Surv. Ophthalmol, 45 (Suppl 2), S221-226 (2001).

21. Ousler, G. W. 3, Hagberg, K. W., Schindelar, M., Welch, D., Abelson, M. B. \& rd „\& The Ocular Protection Index. Cornea, 27, 509-513 https://doi.org/10.1097/ICO.0b013e31816583f6 (2008).

22. Nichols, K. K. et al. The international workshop on meibomian gland dysfunction: executive summary. Invest. Ophthalmol. Vis. Sci. 52, 1922-1929, doi:10.1167/iovs.10-6997a (2011).

23. Connor, C. G., Flockencier, L. L. \& Hall, C. W. The influence of gender on the ocular surface. J. Am. Optom. Assoc, 70, 182-186 (1999).

24. Wan, K. H., Chen, L. J. \& Young, A. L. Efficacy and Safety of Topical $0.05 \%$ Cyclosporine Eye Drops in the Treatment of Dry Eye Syndrome: A Systematic Review and Meta-analysis. The ocular surface, 13, 213-225 https://doi.org/10.1016/j.jtos.2014.12.006 (2015).

25. Sall, K., Stevenson, O. D., Mundorf, T. K. \& Reis, B. L. Two multicenter, randomized studies of the efficacy and safety of cyclosporine ophthalmic emulsion in moderate to severe dry eye disease. CsA Phase 3 Study Group., 107, 631-639 (2000). 
26. Kim, E. C., Choi, J. S. \& Joo, C. K. A comparison of vitamin a and cyclosporine a $0.05 \%$ eye drops for treatment of dry eye syndrome. Am. J. Ophthalmol, 147, 206-213203 https://doi.org/10.1016/j.ajo.2008.08.015 (2009).

27. Demiryay, E., Yaylali, V., Cetin, E. N. \& Yildirim, C. Effects of topical cyclosporine a plus artificial tears versus artificial tears treatment on conjunctival goblet cell density in dysfunctional tear syndrome. Eye \& contact lens, 37, 312-315 https://doi.org/10.1097/ICL.0b013e31822563be (2011).

28. Baudouin, C. et al. A randomized study of the efficacy and safety of $0.1 \%$ cyclosporine A cationic emulsion in treatment of moderate to severe dry eye. Eur. J. Ophthalmol, $\mathbf{0}$, https://doi.org/10.5301/EJ0.5000952 (2017).

29. Leonardi, A. et al. Efficacy and safety of $0.1 \%$ cyclosporine A cationic emulsion in the treatment of severe dry eye disease: a multicenter randomized trial. Eur. J. Ophthalmol, 26, 287-296 https://doi.org/10.5301/ejo.5000779 (2016).

30. Deshmukh, R. et al. Real-world experience of using ciclosporin-A $0.1 \%$ (Ikervis) in the management of ocular surface inflammatory diseases. Br. J. Ophthalmol, https://doi.org/10.1136/bjophthalmol2020-317907 (2021).

31. Miller, K. L. et al. Minimal clinically important difference for the ocular surface disease index. Arch. Ophthalmol, 128, 94-101 https://doi.org/10.1001/archophthalmol.2009.356 (2010).

32. Stonecipher, K. G. et al. The IMPACT study: a prospective evaluation of the effects of cyclosporine ophthalmic emulsion $0.05 \%$ on ocular surface staining and visual performance in patients with dry eye. Clin. Ophthalmol, 10, 887-895 https://doi.org/10.2147/OPTH.S101627 (2016).

33. Guzey, M. et al. Efficacy of topical cyclosporine A in the treatment of severe trachomatous dry eye. Clin Exp Ophthalmol, 37, 541-549 https://doi.org/10.1111/j.1442-9071.2009.02090.x (2009).

34. Rao, S. N. Topical cyclosporine $0.05 \%$ for the prevention of dry eye disease progression. J. Ocul. Pharmacol. Ther, 26, 157-164 https://doi.org/10.1089/jop.2009.0091 (2010).

35. Qiao, J. \& Yan, X. Emerging treatment options for meibomian gland dysfunction. Clin. Ophthalmol, 7, 1797-1803 https://doi.org/10.2147/opth.S33182 (2013).

36. Prabhasawat, P., Tesavibul, N. \& Mahawong, W. A randomized double-masked study of $0.05 \%$ cyclosporine ophthalmic emulsion in the treatment of meibomian gland dysfunction., 31, 13861393 https://doi.org/10.1097/IC0.0b013e31823cc098 (2012).

37. Perry, H. D. et al. Efficacy of commercially available topical cyclosporine A $0.05 \%$ in the treatment of meibomian gland dysfunction., 25, 171-175 (2006).

38. Rubin, M. \& Rao, S. N. Efficacy of topical cyclosporin $0.05 \%$ in the treatment of posterior blepharitis. J. Ocul. Pharmacol. Ther, 22, 47-53 https://doi.org/10.1089/jop.2006.22.47 (2006).

39. Enriquez-de-Salamanca, A. et al. Tear cytokine and chemokine analysis and clinical correlations in evaporative-type dry eye disease. Mol. Vis, 16, 862-873 (2010).

40. Lam, H. et al. Tear cytokine profiles in dysfunctional tear syndrome. Am. J. Ophthalmol, 147, 198205 https://doi.org/e191 (2009). 
41. Pflugfelder, S. C., Jones, D., Ji, Z., Afonso, A. \& Monroy, D. Altered cytokine balance in the tear fluid and conjunctiva of patients with Sjogren's syndrome keratoconjunctivitis sicca. Curr. Eye Res, 19, 201-211 (1999).

42. Solomon, A. et al. Pro- and anti-inflammatory forms of interleukin-1 in the tear fluid and conjunctiva of patients with dry-eye disease. Invest. Ophthalmol. Vis. Sci, 42, 2283-2292 (2001).

43. Turner, K. et al. Interleukin-6 levels in the conjunctival epithelium of patients with dry eye disease treated with cyclosporine ophthalmic emulsion., 19, 492-496 (2000).

\section{Figures}

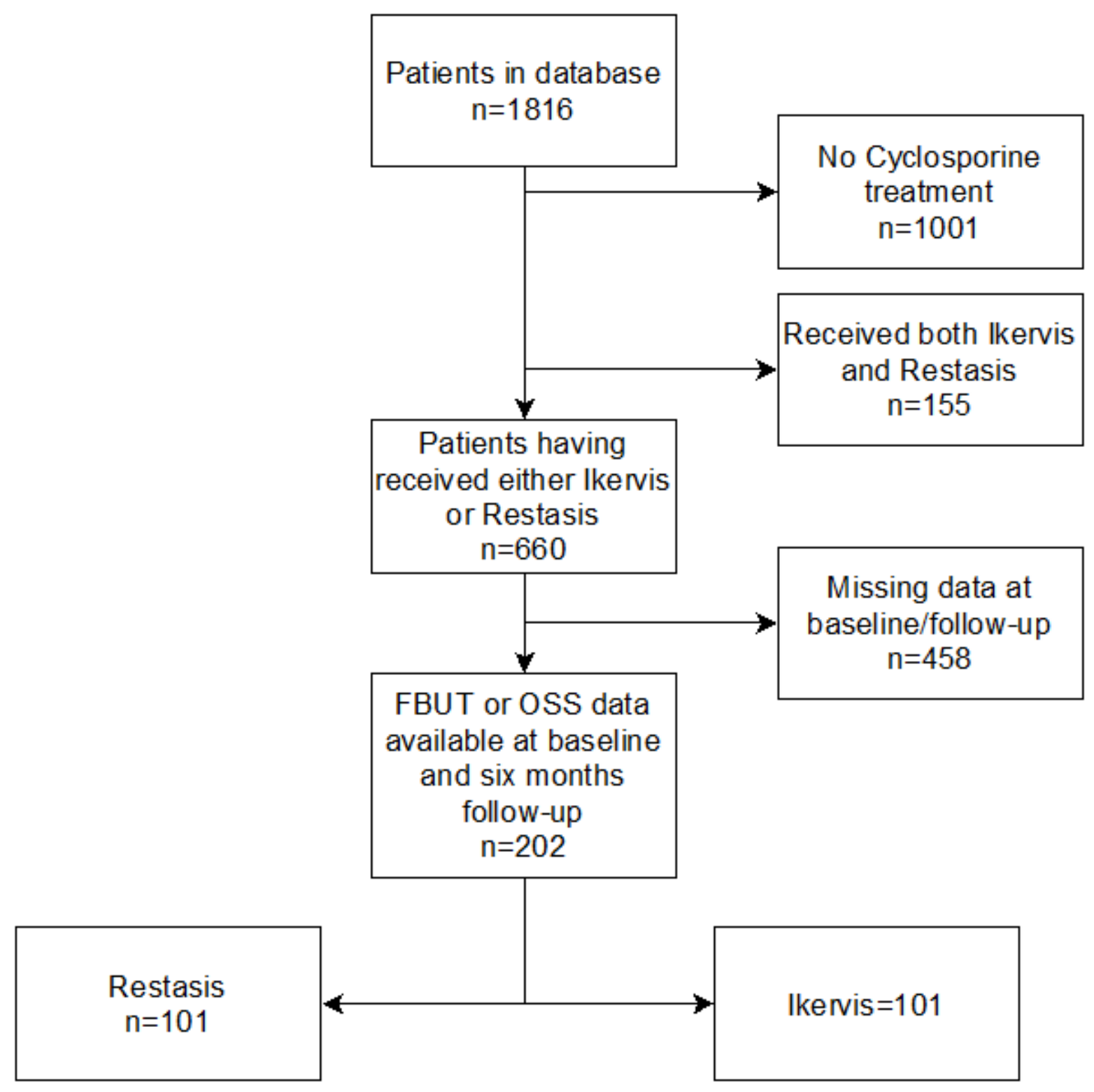

Figure 1

Flow chart of patient inclusion 


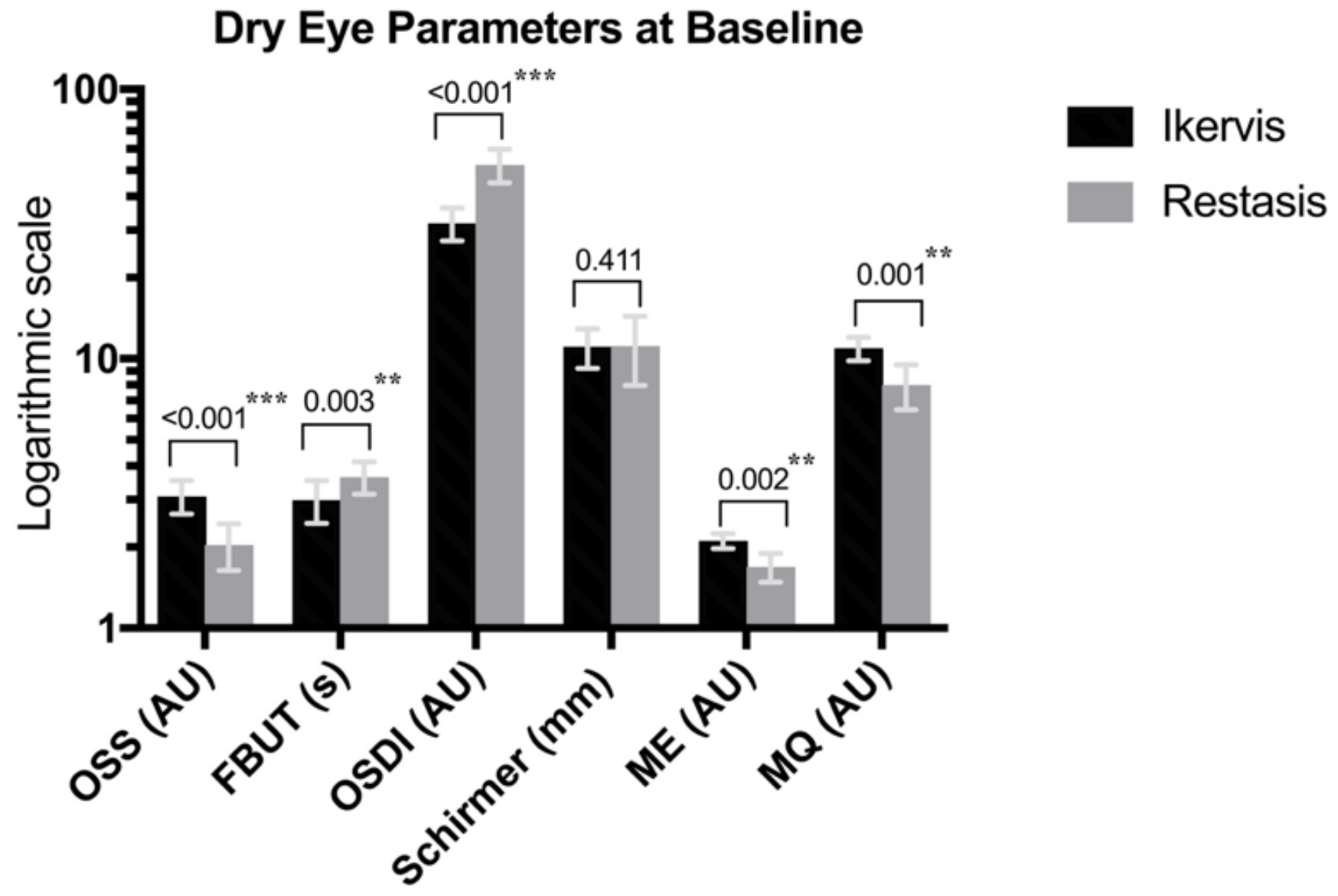

Figure 2

Baseline data. 